Prepared in cooperation with Coastal Protection and Restoration Authority of Louisiana, U.S. Army Corps of Engineers, U.S. Environmental Protection Agency, U.S. Fish and Wildlife Service, Natural Resources Conservation Service, and National Oceanic and Atmospheric Administration

\title{
Classifications for Coastal Wetlands Planning, Protection and Restoration Act Site-Specific Projects: 2008 and 2009
}

Data Series 701 



\section{Classifications for Coastal Wetlands Planning, Protection and Restoration Act Site-Specific Projects: 2008 and 2009}

By William R. Jones and Adrienne Garber

Prepared in cooperation with Coastal Protection and Restoration Authority of Louisiana, U.S. Army Corps of Engineers, U.S. Environmental Protection Agency, U.S. Fish and Wildlife Service, Natural Resources Conservation Service, and National Oceanic and Atmospheric Administration

Data Series 701 


\title{
U.S. Department of the Interior \\ KEN SALAZAR, Secretary \\ U.S. Geological Survey \\ Marcia K. McNutt, Director
}

\author{
U.S. Geological Survey, Reston, Virginia: 2012
}

For more information on the USGS - the Federal source for science about the Earth, its natural and living resources, natural hazards, and the environment, visit http://www.usgs.gov or call 1-888-ASK-USGS.

For an overview of USGS information products, including maps, imagery, and publications, visit http://www.usgs.gov/pubprod

To order this and other USGS information products, visit http://store.usgs.gov

Any use of trade, product, or firm names is for descriptive purposes only and does not imply endorsement by the U.S. Government.

Although this report is in the public domain, permission must be secured from the individual copyright owners to reproduce any copyrighted materials contained within this report.

Suggested citation:

Jones, W.R., and Garber, Adrienne, 2012, Classifications for Coastal Wetlands Planning, Protection and Restoration Act site-specific projects—2008 and 2009: U.S. Geological Survey Data Series 701, 8 p. and 14 maps. 


\section{Contents}

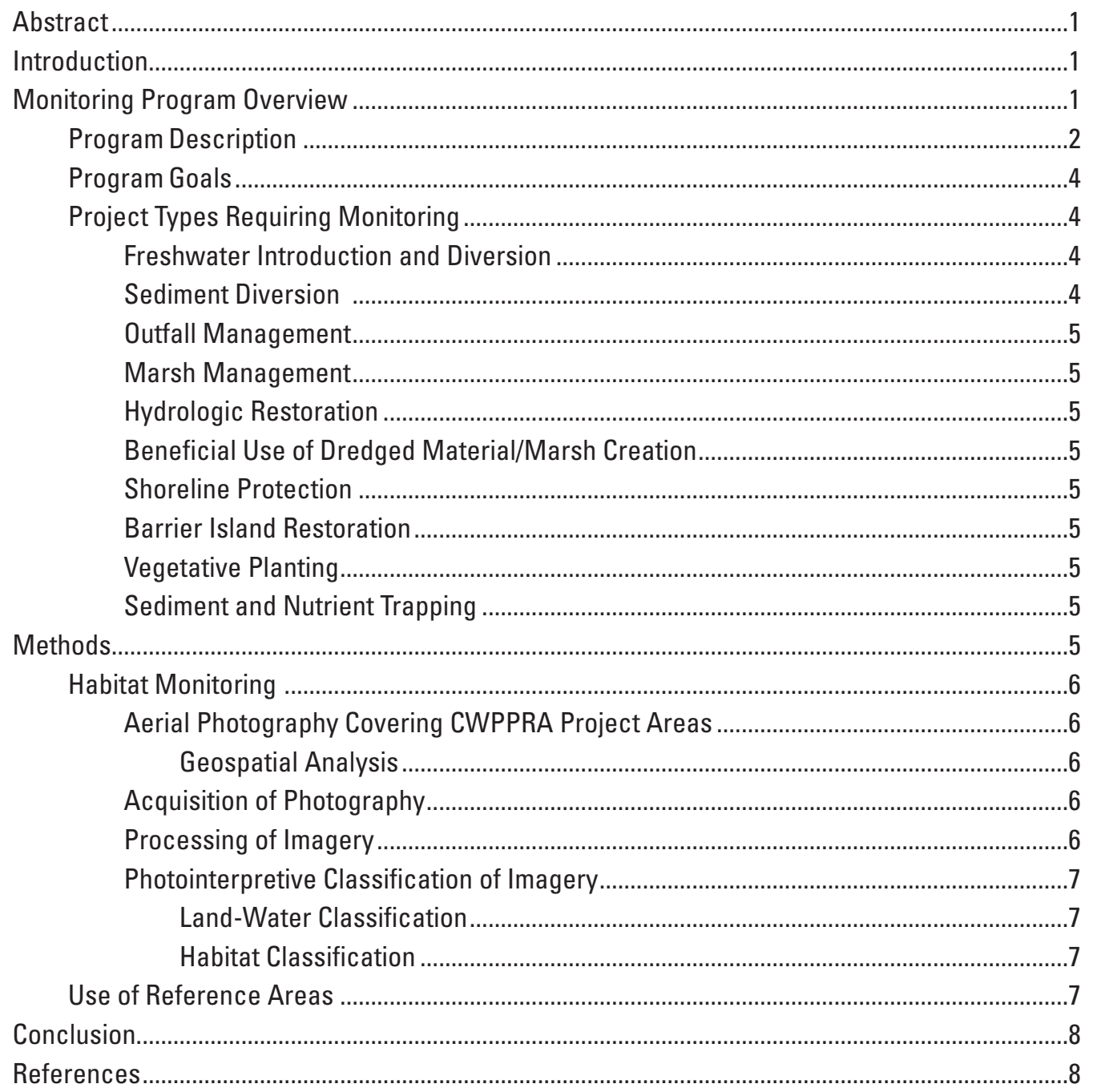




\section{Figures}

1 Locations of Coastal Planning, Protection and Restoration Act projects across coastal Louisiana for which site-specific 2008-9 classification maps were produced. (See table 1 for project naming conventions and further information on associated map products.)

\section{Tables}

1 Summary of site-specific classification maps for Coastal Wetlands

Planning, Protection and Restoration Act projects across coastal

Louisiana, 2008-9. (See fig. 1 for project locations.)

\section{Conversion Factors}

\begin{tabular}{|c|c|c|}
\hline Multiply & By & To obtain \\
\hline \multicolumn{3}{|c|}{ Length } \\
\hline inch (in.) & 2.54 & centimeter $(\mathrm{cm})$ \\
\hline inch (in.) & 25.4 & millimeter $(\mathrm{mm})$ \\
\hline foot (ft) & 0.3048 & meter $(\mathrm{m})$ \\
\hline mile (mi) & 1.609 & kilometer (km) \\
\hline yard (yd) & 0.9144 & meter $(\mathrm{m})$ \\
\hline \multicolumn{3}{|c|}{ Area } \\
\hline acre & 4,047 & square meter $\left(\mathrm{m}^{2}\right)$ \\
\hline acre & 0.4047 & hectare (ha) \\
\hline acre & 0.4047 & square hectometer $\left(\mathrm{hm}^{2}\right)$ \\
\hline acre & 0.004047 & square kilometer $\left(\mathrm{km}^{2}\right)$ \\
\hline
\end{tabular}




\title{
Classifications for Coastal Wetlands Planning, Protection and Restoration Act Site-Specific Projects: 2008 and 2009
}

\author{
By William R. Jones ${ }^{1}$ and Adrienne Garber ${ }^{2}$
}

\section{Abstract}

The Coastal Wetlands Planning, Protection and Restoration Act (CWPPRA) funds over 100 wetland restoration projects across Louisiana. Integral to the success of CWPPRA is its long-term monitoring program, which enables State and Federal agencies to determine the effectiveness of each restoration effort. One component of this monitoring program is the analysis of high-resolution, color-infrared aerial photography at the U.S. Geological Survey's National Wetlands Research Center in Lafayette, Louisiana.

Color-infrared aerial photography (9- by 9 -inch) is obtained before project construction and several times after construction. Each frame is scanned on a photogrametric scanner that produces a high-resolution image in Tagged Image File Format (TIFF). By using image-processing software, these TIFF files are then orthorectified and mosaicked to produce a seamless image of a project area and its associated reference area (a control site near the project that has common environmental features, such as marsh type, soil types, and water salinities.) The project and reference areas are then classified according to pixel value into two distinct classes, land and water. After initial land and water ratios have been established by using photography obtained before and after project construction, subsequent comparisons can be made over time to determine land-water change.

Several challenges are associated with the land-water interpretation process. Primarily, land-water classifications are often complicated by the presence of floating aquatic vegetation that occurs throughout the freshwater systems of coastal Louisiana and that is sometimes difficult to differentiate from emergent marsh. Other challenges include tidal fluctuations and water movement from strong winds, which may result in flooding and inundation of emergent marsh during certain conditions. Compensating for these events is difficult but possible by using other sources of imagery to verify marsh conditions for other dates in time.

\footnotetext{
${ }^{1}$ U.S. Geological Survey

${ }^{2}$ Five Rivers, LLC, for the U.S. Geological Survey
}

\section{Introduction}

In response to accelerated wetland loss in Louisiana, in 1989 the State of Louisiana adopted Act 6 (La. revised statute [RS] 49:213.1) of the Second Extraordinary Session of the Louisiana State Legislature. This State legislation was followed by Federal legislation in 1990 when the U.S. Congress passed the Coastal Wetlands Planning, Protection, and Restoration Act (CWPPRA; Public Law 101-646, Title III [16 USC 3951]). Together these acts have facilitated conservation, restoration, creation, and enhancement of coastal wetlands in Louisiana. The agencies responsible for designing and implementing coastal conservation and restoration projects include the Coastal Protection and Restoration Authority (CPRA) of Louisiana, U.S. Department of Commerce, U.S. Department of Agriculture, U.S. Department of the Interior, U.S. Department of the Army, and the U.S. Environmental Protection Agency.

As part of the monitoring program implemented to assess the ongoing success of the CWPPRA legislation, scientists at the National Wetlands Research Center (NWRC) of the U.S. Geological Survey (USGS; U.S. Department of Interior) produce land-water and habitat classification maps to help assess and document environmental changes related to CWPPRA projects. The maps included in the current report (table 1) compose the 2008 and 2009 collection of maps documenting data acquired at CWPPRA projects across coastal Louisiana (fig. 1). These maps are produced as deliverables to the CPRA of Louisiana, which represents the interests of the State.

\section{Monitoring Program Overview}

As part of CWPPRA legislation, an interagency task force was created and charged with the development and implementation of a comprehensive approach to the longterm conservation and restoration of coastal wetlands. The restoration plans developed pursuant to CWPPRA and coordinating State legislation specifically require evaluation of the effectiveness of each coastal wetlands restoration project 
Table 1. Summary of site-specific classification maps for Coastal Wetlands Planning, Protection and Restoration Act projects across coastal Louisiana, 2008-9. (See fig. 1 for project locations.)

[Project maps are listed in geographical order from west to east. Each project is named according to the hydrologic basin in which it is located. The following abbreviations are for the hydrologic basins of Louisiana, a map of which is available from the Louisiana Coastal Wetlands Planning, Protection and Restoration Act Program (n.d.): CS, Calcasieu/Sabine; TV, Teche/Vermilion; TE, Terrebonne; BA, Barataria]

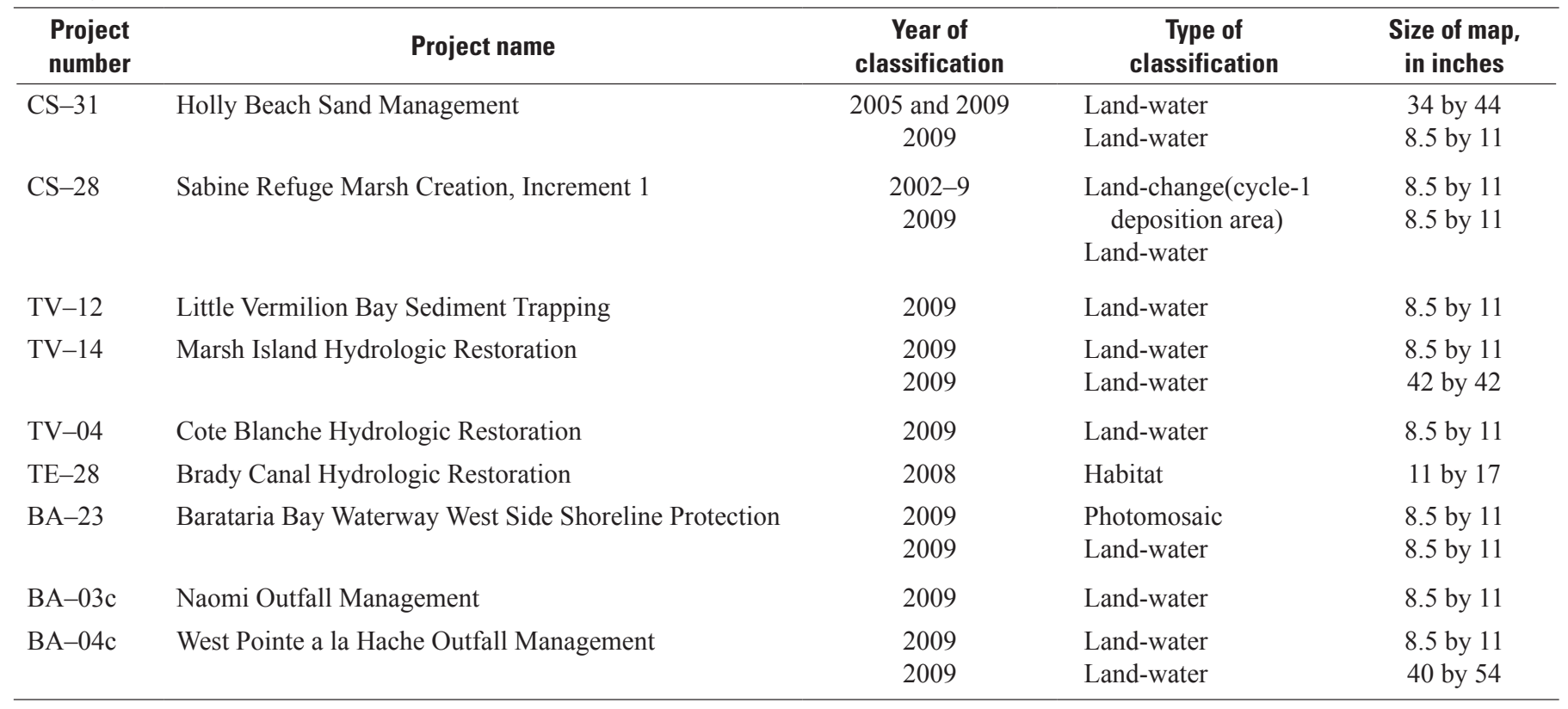

in achieving long-term solutions to arresting coastal wetlands loss. Evaluating these projects required the development of a monitoring program to adequately assess their effectiveness. The named agencies have a responsibility to the State of Louisiana and to the Nation to develop a monitoring program that will effectively ensure the best use of State and Federal funds for the restoration and conservation of wetlands.

Because the mission of CWPPRA is to provide appropriate management plans for the Louisiana coastal zone over the next 50-100 years, long-term monitoring protocols need to be applied on a regional scale to provide the data necessary for effective management and planning. As part of the legislation, CWPPRA required that a report containing a scientific evaluation of the effectiveness of the restoration project be submitted to Congress no more than three years after the completion and submission of the restoration plan and at least every three years thereafter. CWPPRA has now dedicated resources to the monitoring program for $20 \mathrm{yrs}$.

\section{Program Description}

The CWPPRA monitoring program was developed by Monitoring Working Group (MWG) by using a broad-based, standardized approach. Steyer and others (1992) provide a guidance document that can be used to develop projectspecific and basin-wide monitoring plans and cost estimates. The monitoring protocols developed by Steyer and Stewart (1992) call for broadly categorizing project types, goals, and biological variables and standardizing data collection methodologies by using a matrix design. The protocols were developed by subgroups of technical experts for seven categories of monitoring variables, including water quality, hydrology, soils and sediments, vegetative health, habitat mapping, wildlife, and fisheries. This organization provides accessibility to three levels of information - project type, category of variable, and variable - that are cross-referenced and ranked to guide personnel in the development of appropriate monitoring plans.

The CWPPRA Monitoring Program develops monitoring plans and collects data on individual projects on the basis of specific project goals and objectives. The framework within which the plans are developed is based on a basinlevel approach. Monitoring efforts for all projects within a given hydrologic basin are coordinated in order to adequately address secondary or cumulative effects of projects.

Monitoring plans for CWPPRA projects are developed on the basis of the minimum number of monitoring variables necessary to provide sufficient information to determine if project goals and objectives are being met. A subset of the variables that are essential to any given project includes those that generally will be measured for all project types; however, some of the highest priority variables may not be monitored because of limited availability of funds. According to project type, MWG determines which variables are essential in judging project effectiveness and which additional variables may need to be monitored on the basis of project objectives and possible impacts. This list does not preclude other 


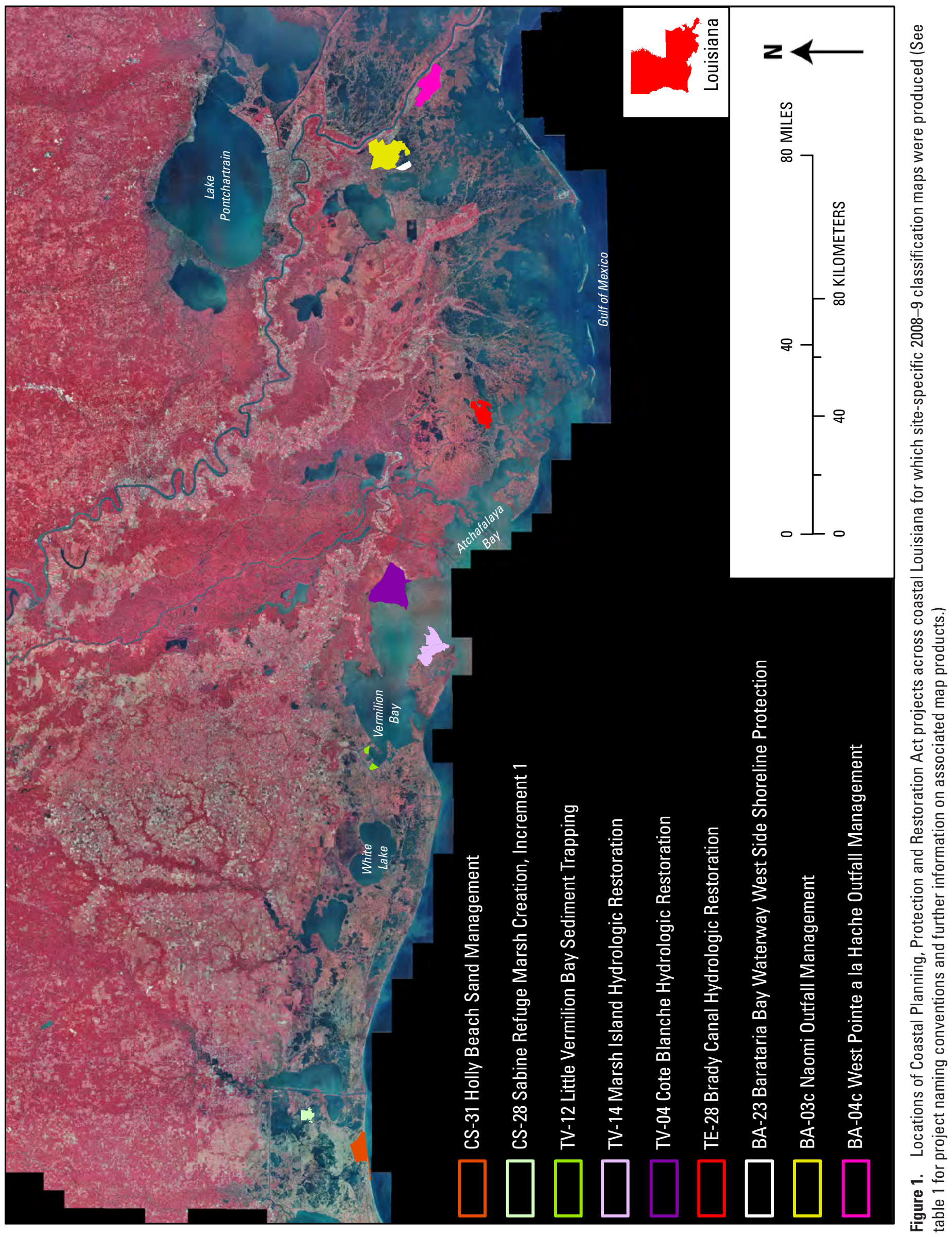


variables from being monitored if determined necessary by Technical Advisory Group (TAG).

The importance of a sound quality assurance (QA) program is acknowledged by CWPPRA and is addressed in the overall program goals. It is specific policy that all environmentally related measurements collected by personnel of CPRA and USGS NWRC are of known and documented quality. This level of assurance is necessary because vast quantities of data are collected. Analyses of these data will ultimately assist in decision making regarding project- and program-level effectiveness; therefore, it is critical that it be of the highest quality.

\section{Program Goals}

Monitoring of projects implemented from the CWPPRA restoration plan must result in the following products:

- "An evaluation of the effectiveness of each coastal wetlands restoration project in achieving longterm solutions to arresting coastal wetlands loss in Louisiana" (U.S. Congress, 1990, Sec. 303 [b][4] $[\mathrm{L}])$, and

- "A scientific evaluation of the effectiveness of the coastal wetlands restoration projects carried out under the plan in creating, restoring, protecting and enhancing coastal wetlands in Louisiana" (U.S. Congress, 1990, Sec. 303[b][7]).

In order for the above mandates to be achieved, the monitoring efforts must generate results that aid in determining the effectiveness of existing projects, the beneficial modification of existing projects, and the design of future projects. Most importantly, monitoring data collected from existing projects must support future decisions on selection of projects proposed for creating, restoring, protecting, and enhancing the coastal wetlands of Louisiana. Comparison of results among projects of similar types is a way to determine which projects are most effective in achieving long-term solutions to arresting coastal wetlands loss.

The collection, analysis, and interpretation of highquality ecological, hydrological, and climatological data are critical steps to the success of monitoring efforts and the mission of CWPPRA. These steps are achieved by implementing the following practices:

1. Pragmatic data collection methods based on specific goals and objectives and developed by using sound experimental design,

2. Unbiased evaluation of data to determine the effectiveness of wetland projects,

3. Documentation and dissemination of project data, and

4. Evaluation of program effectiveness as the knowledge and technology base expands.

Fulfillment of the mission results in appropriate management decisions that ultimately result in the creation, restoration, protection, and enhancement of the coastal wetlands of Louisiana.

\section{Project Types Requiring Monitoring}

Under Act 6 of the Louisiana legislature (La. revised statute [RS] 49:213.1) and CWPPRA, all projects were categorized into ten types, including freshwater introduction and diversions, sediment diversions, outfall management, marsh management, hydrologic restoration, beneficial use of dredged material/marsh creation, shoreline protection, barrier island restoration, vegetative planting, and sediment and nutrient trapping.

A critical step in establishing a successful monitoring program is defining the goals of the management project. For example, a project using dredged material may be built to reduce wave energies and consequential physical erosion or to develop a new soil and sediment base at a proper elevation to restore or maintain vegetated marsh. Each of these projects begins with a hypothesis or set of hypotheses related to the expected change in physical, biological, or chemical variables of the project area. These hypotheses then guide the monitoring program as to which variables will be monitored and how frequently.

\section{Freshwater Introduction and Diversion}

Freshwater introduction and diversion projects are designed to introduce fresh water and alluvial material from available sources to shallow marsh estuaries. Areas targeted for freshwater diversion projects are characterized by saltwater intrusion, sediment subsidence, and shoreline erosion. The primary goal of these projects is to enhance proximal wetlands by increasing the availability of fresh water, nutrients, and sediment that will be provided by the freshwater diversions. Management of the outfall will route the fresh water through the wetlands and provide greater deposition of sediments in the marsh to offset subsidence, increase availability of nutrients to vegetation, and create a more gradual release of fresh water to the benefit of wildlife, fish, and shellish.

\section{Sediment Diversion}

Sediment diversions are projects that increase deposition - through sediment accretion - of river-borne sediment in shallow bay areas that cannot keep pace with the rate of subsidence. A small-scale sediment diversion project is designed around the concept of natural crevasse-splay development. Where a breach occurs in the bank of a river, sediment infilling begins within the surrounding distributary bays, and crevasse-splay sediment eventually becomes subaerial and established with marsh vegetation. Large-scale sediment diversions on the Mississippi River are designed to be similar to large natural crevasses, such as the one at Baptiste Collette, La. The primary goal of the project is to create and manage crevasses through the natural levee ridges of rivers and 
major distributaries so that the natural land-building process can create emergent and submergent aquatic communities critical to the overall productivity of the deltaic systems.

\section{Outfall Management}

Outfall management projects are used to maximize the benefits of a river diversion project. This technique involves regulating water levels and direction of water flow to increase the dispersion and retention time of fresh water, nutrients, and sediment in the marsh. The water flow may be regulated by a combination of gates, locks, weirs, canal plugs, and gaps cut in artificial levee banks.

\section{Marsh Management}

In marsh management projects, engineered structures actively manipulate local hydrology to control water levels and salinity, while concurrently allowing ingress and egress of marine organisms. Marsh management plans generally incorporate existing canal spoil banks, the construction of short levees to connect these spoil banks, the installation of water control structures, and/or the construction of pumps and other control structures to introduce fresh water into the managed area and keep out saline water. The main goals of marsh management are to minimize the loss of and promote the growth of emergent and submergent plant communities by reducing salinities, stabilizing water levels, and restricting tidal exchange.

\section{Hydrologic Restoration}

Hydrologic restoration projects typically are designed to reestablish former hydrologic pathways and flow regimes, with the goal of redistributing fresh water to influence water levels and salinity. Specifically, hydrologic restoration projects tend to reduce rapid tidal fluctuations and improve freshwater retention. These manipulations of the local hydrology aid in the reestablishment of emergent and submergent plant communities.

\section{Beneficial Use of Dredged Material/Marsh Creation}

Open-water bodies and navigational channels are often sources of dredged sediment material that could be beneficially used to create vegetated wetlands or to restore areas of deteriorating marsh. Sediment can be pumped into confined or nonconfined areas to a height conducive to marsh development. Once the dredged material settles, growth of emergent vegetation can be promoted.

\section{Shoreline Protection}

Shoreline protection projects use structural and nonstructural measures, such as breakwaters, bulkheads, revetments, longyard tubes, wave-damping fences, and levees, to reduce wave energies and erosive action. Critical shoreline areas threatened with hydrological breaches can be protected to prevent wave erosion and water exchange from jeopardizing the physical integrity of the shoreline and adjacent marshes. Vegetation can be incorporated into the shoreline protection design to create habitat as well as provide an additional erosion buffer.

\section{Barrier Island Restoration}

Barrier islands provide protection to back-barrier bays, estuaries, and marshes. This protection includes reducing effects of erosion, wind, and wave energies; dissipation of storm surges; and prevention of saltwater intrusion. Over the last century, the barrier islands of Louisiana have been reduced by approximately 40 percent, resulting in loss of habitat and protection for the coastal mainland. Barrier island restoration projects, which include creation of barrier islands or augmentation of existing islands, are needed to reestablish this natural protective zone. The objectives of these projects are to increase the height and width of the barrier island and close any shoreline breaches by using dredged materials and vegetation.

\section{Vegetative Planting}

Vegetative planting projects are designed to introduce suitable plant species into deteriorating marsh areas and along eroding shorelines to provide a buffer against erosive wave action. Vegetative plantings also provide many other functions, such as sediment stabilization, sediment trapping, and habitat value.

\section{Sediment and Nutrient Trapping}

Sediment and nutrient trapping projects use structural devices such as brush fences or earthen berms to reduce wave energies, promote the deposition of suspended sediment, and increase water clarity. Project-type goals are to reduce erosion of windward marsh edges, promote the growth of emergent vegetation, and increase the overall productivity of the area.

\section{Methods}

High-resolution, color-infrared aerial photography is acquired for each CWPPRA project several times during its life span. When acquisition is complete, all photography is reviewed for complete coverage, tone and quality. Once the photography is accepted, it is then rectified and mosaicked to provide a seamless image of the project area. All rectification 
meets or exceeds the horizontal National Mapping Accuracy Standards for a given scale.

\section{Habitat Monitoring}

Aerial photography and digital imagery are the primary mapping mediums for habitat monitoring. Over 100 wetland restoration projects across Louisiana are funded by CWPPRA, and for each project there is an established schedule for photography acquisition. Acquisition and classification of aerial photography are conducted by scientists at the USGS NWRC in Lafayette, La.

\section{Aerial Photography Covering CWPPRA Project Areas}

The level of effort needed to establish baseline conditions, as described in each site-specific monitoring plan, differ depending on the project type. All of the restoration projects for which photography is collected require horizontal controls to be established in the field by using the Global Positioning System (GPS) for georeferencing. Georeferences are used for the development of project base maps,

photograph rectification, and replication of mapping for future trend analyses.

\section{Geospatial Analysis}

A coding scheme is used to identify the type of project, the project name, the type of data, the date the data were collected, and the location where the data were collected for each sample. The location will be provided in either latitude/ longitude or UTM coordinates. These steps are needed to ensure that sufficient documentation exists for verification of data accuracy. Data coding is the responsibility of Geoscience Specialists and oversight will verify that all data are properly coded to ensure compatibility with the CWPPRA Regional GIS Data Base.

All spatial data conforms to an Executive Order dated 11 April 1994, describing standardized methods of data acquisition and access. The proper coding of spatial data is the responsibility of the Supervisory Geographer and GIS Specialist to ensure compatibility with the CWPPRA Regional GIS Data Base.

\section{Acquisition of Photography}

Analog aerial photographs are acquired by using the Zeiss RMK camera (Carl Zeiss AG, Oberkochen, Germany) at various scales depending on the project size, as follows: $1: 6,000$ [200 acres or less], 1:12,000 [200 to 20,000 acres], and 1:24,000 [over 20,000 acres]. Project areas for which aerial photographs must be collected are identified by July 1 each year, and photographs are acquired during late fall (prior to senescence) in order to obtain peak biomass for emergent marsh. In the event that conditions arise whereby photography cannot be obtained during this period, plans are made to acquire the photography during the next fall season. When data for a successive year are to be collected for a project, arrangements are made to collect the data for that year on a date that is as close as possible to the date/season data were collected in previous years.

Because afternoon weather conditions (such as afternoon thunderstorms, haze, and cloud cover) are often uncertain, personnel of a contracting company will take vertical photographs, free of clouds, between 10:00 a.m. and 3:00 p.m. to minimize shadowing. The sun angle must not be less than 45 degrees. Photographic images of marsh vegetation and open water are acquired by using a stabilized camera mounted on the aircraft. The scale of the photography is held as close as possible to the required scales for all photos. A 60 percent end lap and 20 percent side lap are required for the photography, which allows the photointerpreter to map the images in stereo. GPS navigation with digital readout in the airplane cabin is the minimum accepted. The contracting personnel acquire high quality transparency film for the project. A minimum of two 9- by 9-inch frames is acquired at the beginning of each flightline to reduce flightline syndrome on usable photography. All duplicate transparencies are individually made by using an automatic dodging printer that reduces color differences between the original and the duplicates.

\section{Processing of Imagery}

The mosaicking and orthorectification of aerial photography is outsourced to a subcontractor who uses proprietary software to provide scientists of USGS NWRC with orthorectified deliverables. All rectification meets or exceeds horizontal National Mapping Accuracy Standards for a given scale.

The mensuration procedure is part of the rectification process and is performed in two separate phases. The first phase is to transfer control points from a Digital Orthophoto Quarter Quadrangle (DOQQ) to the new imagery. The X and $\mathrm{Y}$ coordinates for the image are determined by using the DOQQ, and the $\mathrm{Z}$ coordinate is determined by using a Digital Elevation Model (DEM) that is downloaded from U.S. Geological Survey (2010). The DEMs correspond to specified areas that are being photointerpreted. A sufficient number of points (usually 10-20) are transferred to interpret perimeter images and some interior images. The second phase is to transfer common points between adjacent photographs, both in-line and cross-strip. Typically, nine points are transferred between photos. Initial estimates of the ground coordinates and estimates of the elevation of these points are determined by the DEM. Once the control and pass points are measured, an aerotriangulation is performed by using the measurement data and the initial estimates of ground point coordinates, aircraft position, and orientation. The results of the aerotriangulation (AT) are examined, the outliers are 
eliminated, additional points are added (if necessary), and the AT is repeated until a satisfactory result is achieved. The images are then orthorectified and mosaicked.

\section{Photointerpretive Classification of Imagery}

An important component of the CWPPRA monitoring program is the classification (by land-water and by habitat) of aerial photography by scientists at the USGS NWRC.

\section{Land-Water Classification}

Each time high-resolution, color-infrared aerial photography is acquired, a land-water classification is conducted. An unsupervised classification is performed by using Leica (ERDAS Imagine, Norcross, Georgia) software. When performing the unsupervised classification process, maximum iterations are set to 30 , and the convergence threshold is set at 0.980 . Depending on the color balance, tone, and other aspects of the photography, the number of classes is set between 50 and 100. If it is determined that the maximum iterations have been reached before the convergence threshold is achieved, the maximum iterations will be increased to ensure the convergence threshold is achieved. This procedure results in a thematic raster image with 50-100 different classes, depending upon the range of pixel values. These individual classes are then interpreted to be either land or water based upon photointerpretation. Ancillary datasets from 1998 through 2010 are used to help classify areas that are difficult to identify. The file is then manually edited to correct any misclassified pixels. The finished classification is recoded into the two classes, land and water. All areas characterized by emergent vegetation, wetland forest, scrub-shrub, or uplands are classified as land, while open water, aquatics and mud flats are classified as water. Occasionally, a third class-flooded lands - is used when hurricanes or severe environmental impacts have imposed special mapping characteristics. After completion of the classification process, the GIS specialist will perform a quality assurance (QA) self-check of the results. In addition, a second GIS specialist will perform a final, in-house quality control (QC) review to assure accuracy and data integrity. Difficult areas wherein the classification remains in question are referred to a photointerpreter for final review.

\section{Habitat Classification}

All photointerpretation of habitat adheres to protocols and standards used by the U.S. Fish and Wildlife's National Wetlands Inventory (NWI) Program. The NWI classification system is outlined in the "Classification of Wetlands and Deepwater Habitats of the United States" (Cowardin and others, 1979). For habitat classification, certain types of restoration projects (such as vegetative plantings or shoreline protections) may only require aerial photography, while others (for example, hydrologic restoration or marsh management) require detailed habitat mapping or land/water classification in order to assess restoration success or failure. The basic goal of habitat mapping is to provide consistency across products by using the NWI classification system. Use of this classification system also ensures that wetland habitat changes are accurately and similarly assessed throughout the life of a project. For those projects requiring detailed mapping, aerial photography is photointerpreted.

To begin the photointerpretation process, the digital mosaic of the project area is brought into ArcMap (Environmental Systems Research Institute [ESRI], Redlands, California) software. Habitat types are then delineated by overlaying project area boundaries onto the imagery and editing the features. Ancillary datasets from 1998 through 2010 are used to help classify areas that may be difficult to identify. Imagery of the project area is also viewed in stereo, which helps determine vegetation height and proper classification. After completion of the classification process, the photointerpreter performs a QA self-check of the results. In addition, a second photointerpreter performs a final in-house QA check to further ensure data accuracy and integrity. After scientists of the NWRC have completed QA/QC protocols, the data are sent to the CPRA for review and comment. Personnel of CPRA have field experience of the project areas and can give critical feedback on the accuracy of the data. If changes are suggested, NWRC scientists review the area in question and incorporate all data to make changes as necessary. After all reviews and questions are answered, the final data product is ready for map production, and the map is submitted to an online distribution source.

\section{Use of Reference Areas}

Monitoring of reference areas in relation to project areas provides a means to achieve statistically valid comparisons, and is, therefore, the most effective means of evaluating project success.

If appropriate reference areas are available, they are always included in the project design to allow for interpretation of the influence of temporal and spatial variation on projects. When a monitoring project lacks a reference area, the difference between mean values obtained before and after project creation may be misinterpreted. Long-term mean values are often averages that do not adequately represent rates or conditions that vary in space or time.

Selection of a reference area is ideally performed before project initiation. Reference areas should be ecologically similar to the project area yet located far enough away so as not to be influenced by the project. Potential reference areas can be selected by use of the Wetland Value Assessment Methodology (Environmental Work Group, 2006) methods or by use of more basic comparisons of structural and functional attributes. Appropriate reference areas are more likely to be found for smaller project areas.

In many areas of Louisiana, appropriate reference areas cannot be identified. In addition, the extent of wetland 
modification (both planned and unplanned) occurring in this region often results in the loss of reference areas before monitoring efforts are completed. Occasionally, and especially in the case of very large projects (for example, sediment diversions and freshwater diversions from the Mississippi River or watershed projects), it may be difficult to select reference areas that adequately reflect the same marsh type and function as those being affected by the project. In these cases, the following two strategies can be adopted:

- Monitoring before and after project implementation: The disadvantages of this strategy include delay in implementation, temporal variability, and the inability to clearly identify cumulative impacts of the project in comparison to unaffected areas. In addition, monitoring before and after implementation cannot ensure that the same events are being monitored for comparison; therefore, interpretation of the results will be difficult. Nevertheless, such monitoring does provide some indication of project performance and impact.

- Baseline data collection: This step is especially important in areas where reference areas cannot be selected for monitoring. As a "once only" data collection program, such collection does not delay project implementation as much as does full-scale monitoring before implementation [as in (1)]. In addition, this strategy provides a datum against which changing biological variables can be compared. In some cases, an existing database might be considered appropriate as baseline data. In such instances, an interagency team of experts or their scientific advisors should be convened to evaluate the suitability of the existing database for this purpose.

\section{Conclusion}

Accelerated wetland loss is a reality in the State of Louisiana. When the U.S. Congress passed the Coastal Wetlands Planning, Protection and Restoration Act (CWPPRA) in 1990, it facilitated a comprehensive approach for long-term goals of the conservation, restoration, creation, and enhancement of wetlands in Louisiana. The past and future success of CWPPRA is dependent upon its monitoring program, which is carried out by State and Federal agencies to determine the effectiveness of these restoration efforts.
The collection, analysis, and interpretation of high-quality ecological, hydrological, and climatological data are critical components to the success of the greater mission and monitoring efforts for each project. By using color-infrared aerial photography to interpret wetland change, detailed habitat and land-water classifications are performed to determine land-to-water ratios and project success. Because the U.S. Congress, through CWPPRA, has dedicated resources to this monitoring program for twenty years, there has been a stable commitment to the continued development and advancement of restoration activities to improve long-term wetland restoration throughout coastal Louisiana.

\section{References}

Cowardin, L.M., Carter, Virginia, Golet, F.C., and LaRoe, E.T., 1979, Classification of wetlands and deepwater habitats of the United States: U.S. Fish \& Wildlife Service FWS/OBS-79/31, accessed April 18, 2012, at http://www. fws.gov/wetlands/Documents/Classification-of-Wetlandsand-Deepwater-Habitats-of-the-United-States.pdf.

Environmental Work Group, 2006, Coastal Wetlands Planning, Protection and Restoration Act wetland value assessment methodology - Introduction: Coastal Wetlands Planning, Protection and Restoration Act Program, 4 p., accessed May 23, 2012, at http://acoast.gov/reports/wva/WVA\%20 Introduction.pdf.

Louisiana Coastal Wetlands Planning, Protection and Restoration Act Program, n.d., Coastal Louisiana basins: Louisiana Coastal Wetlands Planning, Protection and Restoration Act Program Web Site, accessed May 23, 2012, at http://lacoast.gov/new/About/Basins.aspx.

Steyer, G.D., Raynie, R.C., Steller, D.L., Fuller, Deborah, and Swenson, Erick, 1995, Quality management plan for Coastal Wetlands Planning, Protection, and Restoration Act Monitoring Program: Baton Rouge, Louisiana Department of Natural Resources, Coastal Restoration Division, OpenFile Series No. 95-01, 97p. (Revised June 2000.) 


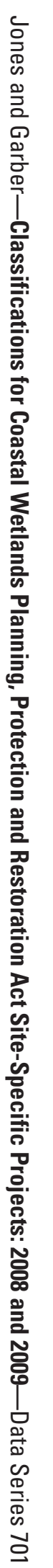

